\title{
MODELLING AND SIMULATION TOOLS FOR INTEGRATING FORWARD AND REVERSE LOGISTICS: A LITERATURE REVIEW
}

\author{
Giulio Paolo Agnusdei ${ }^{(a)}$, Maria Grazia Gnoni ${ }^{(b)}$, Fabiana Tornese ${ }^{(\mathrm{c})}$ \\ (a),(b),(c)Department of Innovation Engineering, University of Salento, Lecce \\ (a) giuliopaolo@agnusdei@ studenti.unisalento.it, ${ }^{(b)}$ mariagrazia.gnoni@ unisalento.it, ${ }^{(c)}$ fabiana.tornese@ unisalento.it
}

\begin{abstract}
The scientific and technical interest towards sustainability issues is increasing in the industrial sector; thus, closed-loop supply chains are getting more and more diffused. As recycling and remanufacturing strategies are becoming a common practice, the importance of reverse logistics is nowadays increasing. Practitioners need to face with both strategic and operational level decisions related to the coordination of direct and reverse logistic flows. While several reviews are available on reverse logistics and closed-loop supply chains, a summary of scientific literature on integrated forward and reverse logistics is still missing. This paper proposes a review of the literature focused on how to integrate forward and reverse logistics in the industrial sector. The main purpose is to identify advantages and criticalities of current tools highlighted by researchers on this topic, with particular attention to modelling and simulation tools. A critical analysis on the benefits and challenges of the main methods identified is proposed. A discussion about potentialities provided by simulation modelling is also discussed.
\end{abstract}

Keywords: integrated forward-reverse logistics, simulation modelling, closed-loop supply chains, literature review.

\section{INTRODUCTION}

In the last 20 years, reverse logistics flows have been growingly integrated in supply chains to guarantee the recovery of products and materials at the end of their useful life (Islam and Huda 2018). Reverse logistics (RL) involve activities in the waste management sectors as well as product recovery in industrial supply chains. On one side, legislations worldwide are pushing towards waste reduction and material recovery, especially in specific sectors (such as the waste from Electronic and Electric Equipment, EEE), lately promoting Circular Economy (CE) models to replace consumption-based linear systems (Govindan et al. 2015). The CE paradigm strongly relies on the integration of direct and reverse logistics to keep materials in the economic system and prevent them from becoming waste (Elia et al. 2016; Ellen MacArthur Foundation 2013). On the other side, material recovery and remanufacturing activities are proving to be potentially profitable for companies in the manufacturing sector (Guide and Van Wassenhove 2009). In this scenario, the problem of the integration of forward and reverse $(\mathrm{F} / \mathrm{R})$ logistics in a closed-loop supply chain (CLSC) is being studied from researchers with different modelling approaches, in order to optimize the performance of the CLSC and maximize profits for the company. While scientific literature has been focusing on CLSC and reverse logistics for two decades, and several reviews are already available on the topic, highlighting the main challenges and opportunities, a specific focus on the integration of $F / R$ flows is still missing. This paper tries to fill this gap, providing a literature review about the main modelling and simulation methodologies used to design and manage integrated $F / R$ flows. In the next section, a background on the main contexts and issues in the integration of $F / R$ flows is provided. Section 3 shows the methodology followed, while the literature review is provided in section 4. Section 5 offers a discussion about the use of simulation modelling in this sector, while conclusions are drawn in Section 6.

\section{THE INTEGRATION OF FORWARD AND REVERSE LOGISTICS IN A CLOSED- LOOP SUPPLY CHAIN}

A traditional supply chain involves all the actors that participate in the process of value creation for the final customer, from suppliers, manufacturers, to distributors, wholesalers, retailers and logistics operators, including all the activities traditionally indicated as forward logistics. In the last decades, RLs became more and more important, allowing to recover products and materials from the end customer and send them back to different echelons of the supply chain, enabling several possible end-of-life (EOL) scenarios, such as reuse, repair, remanufacturing, recycling.

A CLSC integrates both the forward and the reverse logistics flows, designing and managing the operations with the aim of maximizing the value creation (Coenen et al. 2018; Govindan et al. 2015). An example of a generic CLSC is given in Figure 1. The coexistence of these two flows increases the system complexity and pose some challenges in logistics, related to network design, production planning, fleet management, operations management. Two main issues can be 
identified: the first problem is to address is the possibility of coordinating forward and reverse flows in last-mile logistics, combining the delivery to the final customer with the collection of EOL products, which can be convenient if both the operations are managed by the same actor. This coordination is already in place in several business-to-business (B2B) contexts: to name a few examples, new tires distribution to mechanic's workshops is often combined with the collection of used ones; a similar dynamic can be found in pallet management models where direct interchange of new and used pallets is put in place (Elia and Gnoni 2015). The "one-to-one" service operated by retailers of electric and electronic equipment for big devices (e.g. white goods) that collect the used device when the customer buys a new one, is another example of simultaneous delivery and pickup (SDP), in the business-to-consumer (B2C) context.

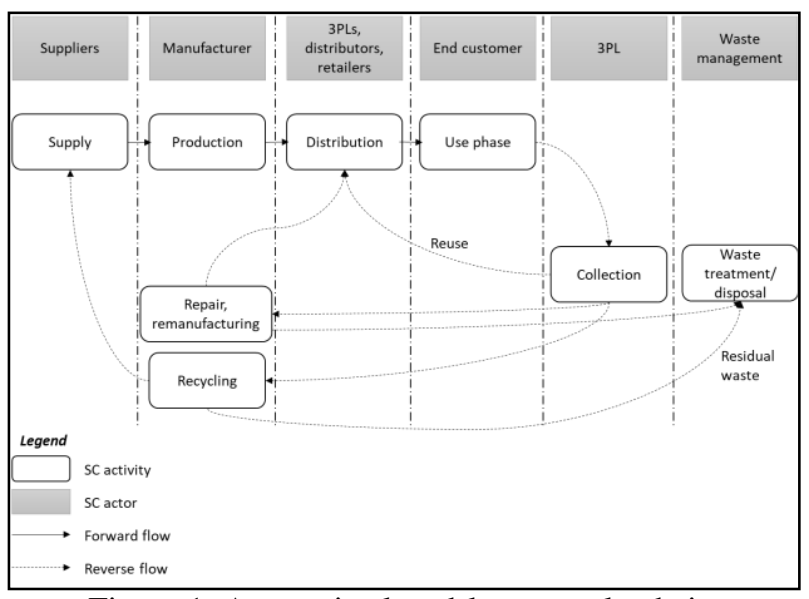

Figure 1: A generic closed-loop supply chain

The second main problem is related to the high uncertainty of return flows in a CLSC (Ponte et al. 2019). While forward flows are usually managed based on more or less accurate forecasts of the end customer's demand, considering the production capacity of the manufacturer and planning production and distribution accordingly, it is not always simple to collect data about returned or EOL products. First of all, different types of reverse flows can coexist in a SC, according to the nature of the unit returned. The main types are summarized as follows:

- New returned products: this category includes new items that have been bought by the customer but never been used, and returned for different possible reasons (e.g. wrong size, customer's dissatisfaction, etc.). This flow is particularly relevant in e-commerce, but is also present in traditional retail. New returned products are usually inspected for quality and then restocked, if compliant.

- Defective products: this includes the used products that are returned for maintenance to the manufacturer. They usually undergo repair/refurbishment (according to the level of damage) and are shipped back to the customer, or can be replaced with new ones while they are remanufactured/recycled or disposed.

- EOL products: used products at the end of their life that the customer does not use anymore. Like defective products, these products can be reused, repaired, remanufactured or recycled according to their state and functionality, and can get back in the forward SC.

- Waste materials: this includes all products and materials that are not recoverable and undergo waste treatment or disposal

For each flow type, the return rate during time can vary sensitively according to several factors, e.g. users' habits and behavior, market fluctuations that can foster (or limit) the sales of new products substituting used ones, defectiveness of new products that are sent back to the manufacturers, etc. For example, the amount of new returned products can vary from an average of 8$10 \%$ in brick-and-mortar to $20-30 \%$ in e-commerce: one common example is represented by the apparel sector, where often customers buy online, try the items at home and ship back those they do not like (Orendorff 2019; Saarijärvi et al. 2017). This type of customer behavior is not easily predictable, although it can be more prominent in specific sectors. Consequently, a high uncertainty and variability of return flows can increase the SC complexity, since a full coordination of forward and reverse flows cannot easily be reached. To cite a few examples, a high percentage of new products returns would require an adjustment of the data about sales, therefore of the actual demand of customers. The flow of repaired and remanufactured products has to be matched with the customer demand for repaired or remanufactured products, and a perfect correspondence between demand and offer is not always the case. Similarly, recycled materials have to find space in the secondary material market. All these issues make the uncertainty of reverse flows a critical point to address, and the coordination of forward and reverse flows one possible way to address it.

The two issues described can occur differently in different contexts: we propose in this section three examples to better contextualize the problem, summarized in Table 1 .

\subsection{Integration of $F / R$ in Remanufacturing}

Remanufacturing is one of the most diffused contexts in which F/R logistics need to be integrated in a CLSC. It represents not only a material recovery strategy that can benefit the environment, but also a business strategy that can potentially increase a manufacturer's revenue. Moreover, in the last decade it's been acknowledged to be one of the mail pillars of $\mathrm{CE}$, this increasing its adoption as a more effective alternative strategy to waste management that keeps the value of products and materials inside the SC (Jensen et al. 2019). In this context, new circular business models based on the use of a product more than its consumption and the 
recovery of components and materials at the end of its useful life (e.g. leasing) are growingly being studied and implemented by manufacturers (van Loon et al. 2019).

The main return flows involved in remanufacturing are EOL products and defective products, which can be repaired or remanufactured and placed back to market. Considering the two main issues illustrated about CLSC, remanufacturing has its peculiarities.

By analyzing the coordination of $\mathrm{F} / \mathrm{R}$ flows, the most relevant factor to be evaluated is the logistics organization, starting from the identification of collection points, which often correspond to point of sales. As previously mentioned, this condition occurs especially when use-based business models are applied (Gnoni et al. 2017) as for retailers of large EEE. When retailers are also collection points, F/R flows can be managed simultaneously, resulting in a vehicle routing with SDP. When collection points are not part of the forward logistic network, the vehicle routing problem (VRP) is with mixed deliveries and pickups (MDP) (Wassan and Nagy 2014).

Regarding the uncertainty of return flows, this is a crucial issue for business models based on remanufacturing, since not only the logistics operations have to be planned according to the actual return flow, but also the remanufacturing operations, that need to be matched with the demand of remanufactured products from the secondary market. This issue can be partly overcome through accurate sales forecasts of new products, that allow to estimate substitutions of used products, while it is even more controlled in use-based business models, where usually the contract with the customer establishes the period of time after which the product can be returned or substituted.

Table 1: Main features of the three contexts analyzed

\begin{tabular}{|c|c|c|c|}
\hline Context & $\begin{array}{c}\text { Flow } \\
\text { involved }\end{array}$ & $\begin{array}{c}\text { Coordinati } \\
\text { on F/R } \\
\text { logistics }\end{array}$ & Uncertainty \\
\hline $\begin{array}{c}\text { Remanufac } \\
\text { turing }\end{array}$ & $\begin{array}{c}\text { EOL } \\
\text { products, } \\
\text { defective } \\
\text { products }\end{array}$ & $\begin{array}{c}\text { SDP or } \\
\text { MDP } \\
\text { models }\end{array}$ & $\begin{array}{c}\text { coordination } \\
\text { of new and } \\
\text { remanufactur } \\
\text { ed products }\end{array}$ \\
\hline WEEE & $\begin{array}{c}\text { EOL } \\
\text { products }\end{array}$ & $\begin{array}{c}\text { Not } \\
\text { possible }\end{array}$ & $\begin{array}{c}\text { High } \\
\text { variability of } \\
\text { return flows }\end{array}$ \\
\hline $\begin{array}{c}\text { E- } \\
\text { commerce }\end{array}$ & $\begin{array}{c}\text { New } \\
\text { returned } \\
\text { products, } \\
\text { defective } \\
\text { products }\end{array}$ & $\begin{array}{c}\text { SDP or } \\
\text { MDP } \\
\text { models }\end{array}$ & $\begin{array}{c}\text { Extreme } \\
\text { variability of } \\
\text { return flows }\end{array}$ \\
\hline
\end{tabular}

\subsection{Integration of $F / R$ in Waste of Electronic and Electric Equipment (WEEE) logistic}

Another specific context in which the management of return flows is crucial is the WEEE sector. WEEE is different than other waste flows for its composition and value: EOL electronic products often contain both hazardous materials that need to be properly processed and precious materials that can be recovered with profit.
The EU directive on WEEE establishes some collection channels, together with recycling targets: the "one-toone" policy guarantees to consumers that buy a new device the possibility to leave the old one to the retailer. The "one-to-zero" policy requires big retailers to collect small electronic devices from customers, even when they do not buy a new one. In both scenarios, the retailer has to manage the stock of returned products as a temporary collection point, from which the WEEE is then collected by specialized logistic service providers. Therefore, retailers act both as a delivery point for forward flows and collection point for reverse flows. Next to them, other collection points are often established by municipalities, where users can deliver their waste, including WEEE (Elia et al. 2018).

Since legislation in most countries (e.g. Italy) does not allow to manage products and waste simultaneously, the collection problem in WEEE reverse logistics is not related to the coordination with forward flows, but to collection planning. The complexity of the network, with multiple collection points that have different functions, capacities and WEE generation rates, requires flexible and adaptive models that can monitor the state of each collection point, in order to plan the routing and scheduling accordingly. The main issue in WEEE collection systems is the uncertainty of reverse flows, which depends on customers' behavior, on the different collection models available in the system, on the existence of informal secondary markets where users often sell or give their used EEE. For these reasons, traditional and static collection schemes do not fit the needs of WEEE, while dynamic schemes based on internet-of-things technologies can be much more effective (Elia et al. 2019).

\subsection{Integration of $F / R$ in e-commerce}

The e-commerce sector has been growing considerably in the last years, and last-mile logistics operators have been facing the challenges related to this context (Cárdenas et al. 2017). The reverse logistics of new and defective products is one of these challenges. Product returns in e-commerce can be driven by many different reasons, according to the customer's habits and behavior: Saarijärvi et al. (2017) identified ten types of returning reasons (e.g. a mistake in the type or size of the product, a quality issue, the same product has been found cheaper on another on-line store, etc.). This, of course, increases sensitively the variability of return flows in e-commerce, that can represent up to $30 \%$ of the sales. Another peculiarity of this context is that the delivery point in last-mile logistics varies from case to case: there are not fixed delivery points, since the good is shipped singularly to the buyer's location (instead of being sent in batches to retailers' stores). On the other hand, pickup points for returned products can be fixed locations (like collection points of the logistics operators, or physical retail stores when cross-channel strategies are in place (Radhi and Zhang 2019)) or variable ones, when the service include the homepickup from the customer's location. Since often both 
pickup and delivery are managed by the same 3PL operator, the coordination of $\mathrm{F} / \mathrm{R}$ flows in last-mile logistics can be realized, addressing the VRP with SDP or MDP, according to the nature of shipments. Scheduling and routing need to be dynamic, since both the locations and the delivery/pickup frequency are variable.

\section{METHODOLOGY}

A systematic literature review has been performed to analyze what have been the main methodologies and tools to study the integration of $\mathrm{F} / \mathrm{R}$ logistic flows. The scientific databases Web of Science and Scopus were searched for the review, using different combinations of keywords: "integrated forward reverse logistics", "reverse logistics + last-mile delivery", "forward reverse logistics + simulation". Of the 121 articles found, a first selection was made based on the title and the abstract, including only those that addressed the issue of the integration of $F / R$ logistics flows in a CLSC. The second screening was based on the content of the articles, resulting in a final sample of 78 papers (including publications on international journals and conference proceedings) published until June 2019.

After the selection, articles have been classified according to the year and journal of publication, the problem addressed, the methodology used, the nature of the variables analyzed (stochastic or deterministic) and the objectives pursued (where applicable). This allowed to perform a deeper analysis whose results are presented in the next section.

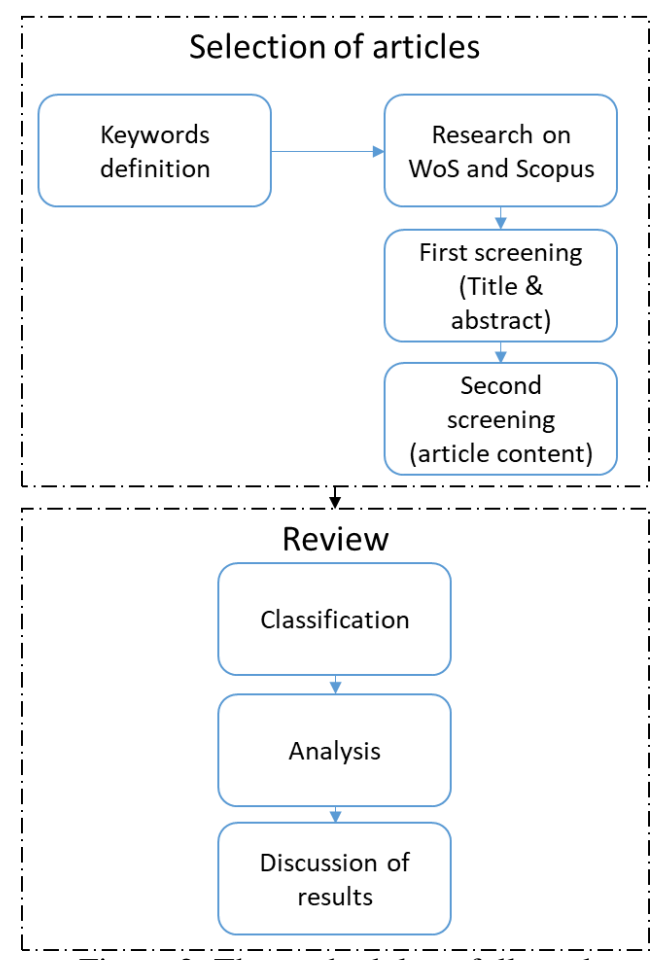

Figure 2: The methodology followed

\section{THE LITERATURE REVIEW}

The 78 papers analyzed were published on a wide variety of sources, including 45 international journals and 16 conference proceedings. Of these, only 14 international journals included more than one of the selected papers: just 3 of them (the Annals of Operations Research, the International Journal of Production Economics and Scientia Iranica) included three articles each. This shows that the problem in analysis invests different fields and is studied from different perspectives, from logistics to economics, from transportation science to mathematical modelling. Concerning the publication period, all of the articles found were published in the last 12 years (2007-2019), as shown in Fig. 3. No trend has been identified, with a number of publications per year ranging from a minimum of two (in 2011) and a maximum of nine (in 2016), and an average of six. This shows a continuous interest in the topic from the scientific community in the last decade that is likely to go on, given the growing diffusion of CLSCs worldwide.

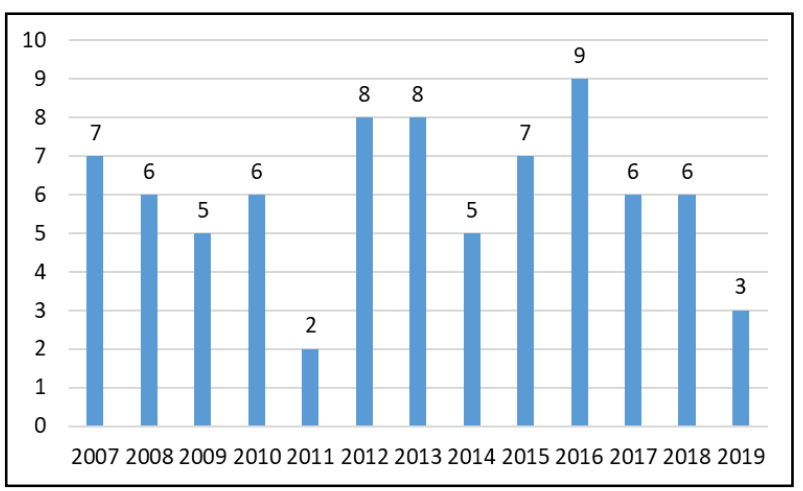

Figure 3: Number of publications per year

The first analyzed factor is the type of main problem addressed in the study. As shown in Table 2, almost half of the articles are focused on a network design and operations problem, while 13 focus only on network design and 10 only on operations in a CLSC. Together, these three clusters include about $75 \%$ of the papers reviewed, listed in Table 3.

Table 2: Focus of the articles analyzed

\begin{tabular}{|c|c|}
\hline Focus & Frequency \\
\hline Network design and operations & 37 \\
\hline Network design & 13 \\
\hline CLSC operations & 10 \\
\hline Inventory model & 4 \\
\hline VRP & 3 \\
\hline VRP with SDP & 3 \\
\hline Long-term behavior analysis & 3 \\
\hline Other & 5 \\
\hline Total & 78 \\
\hline
\end{tabular}

Other 4 works are focused specifically on inventory management in the CLSC, elaborating optimal replenishment policies (Chung et al. 2008; Mitra 2012), lot sizing policies (Kim et al. 2013) and recovery 
policies (Niknejad and Petrovic 2014) to maximize the profit. Seven papers address the vehicle routing problem (VRP), focusing on different aspects of the well-known problem, such as the simultaneous delivery and pickup (SDP) (Gajpal and Abad 2010; Xie et al. 2007; Zhang et al. 2014), the presence of cross-docking facilities (Kaboudani et al. 2018), the coordination of F/R flows (Chang and Liao 2011; Dondo and Méndez 2016).

Table 3: Articles focused on network design and/or operations.

\begin{tabular}{|c|c|}
\hline Focus & Articles \\
\hline $\begin{array}{c}\text { Network } \\
\text { design and } \\
\text { operations }\end{array}$ & $\begin{array}{l}\text { (Al-Salem et al. 2016; Choudhary et } \\
\text { al. 2015; De Rosa et al. 2013; Elahi } \\
\text { and Franchetti 2014; Fattahi and } \\
\text { Govindan 2017; Garg et al. 2014; Guo } \\
\text { et al. 2018; Hatefi et al. 2016; S.M. } \\
\text { Hatefi et al. 2015; S. M. Hatefi et al. } \\
\text { 2015; Hatefi and Jolai 2015, 2014; Ko } \\
\text { and Evans 2007; Lee et al. 2007a, } \\
\text { 2007b, 2013, 2012; Lee and Dong } \\
\text { 2008; Lee and Lee 2012; Lin et al. } \\
\text { 2009; Lu and Zhao 2010; Nobari and } \\
\text { Kheirkhah 2017; Pedram et al. 2017; } \\
\text { Peng and Yao 2007; Pishvaee et al. } \\
\text { 2010, 2009; Rezaei and Kheirkhah } \\
\text { 2017; Roghanian and Kamandanipour } \\
\text { 2013; Ross et al. 2017; Soleimani et } \\
\text { al. 2016; L.-C. Wang et al. 2013; } \\
\text { Wang and Di 2010; Wang and Zhao } \\
\text { 2009; Y. Wang et al. 2013; Yazdi and } \\
\text { Honarvar 2015; Zhou and Xu 2009; } \\
\text { Zohal and Soleimani 2016) }\end{array}$ \\
\hline $\begin{array}{c}\text { Network } \\
\text { design }\end{array}$ & $\begin{array}{c}\text { (Afshari et al. 2016, 2014; Barker and } \\
\text { Zabinsky 2008; Behmanesh and } \\
\text { Pannek 2018, 2016; Chen et al. 2017; } \\
\text { Cilacı Tombuş et al. 2017; Ding 2010; } \\
\text { Djikanovic et al. 2015; Djikanovic and } \\
\text { Vujosević 2016; Easwaran and Üster } \\
\text { 2010; Faccio et al. 2011; Sahyouni et } \\
\text { al. 2007) }\end{array}$ \\
\hline $\begin{array}{c}\text { CLSC } \\
\text { operations }\end{array}$ & $\begin{array}{l}\text { (Chen et al. 2008; Gu and Ji 2008; } \\
\text { Habibi et al. 2019; Jalil et al. 2019; } \\
\text { Jayant and Kumar 2012; Jinlan and Ni } \\
\text { 2007; Keyvanshokooh et al. 2013; } \\
\text { Mehdizadeh et al. 2013; Porkar et al. } \\
\text { 2018; Zhou 2015) }\end{array}$ \\
\hline
\end{tabular}

Three works from the same research group study the long-term behavior of an integrated F/R logistic system under different managerial scenarios (Das and Dutta 2013a, 2013b, 2012). Finally, the last five works address other aspects characterizing an integrated F/R logistics system, adopting qualitative approaches to frame the context (de la Fuente et al. 2008; Jaaron and Backhouse 2016), focusing on restocking and fee policies (Shulman et al. 2009), on government policies influencing the recycling quality (Tan and Guo 2019), or on the selection of third party forward and reverse logistics providers (Govindan et al. 2019).

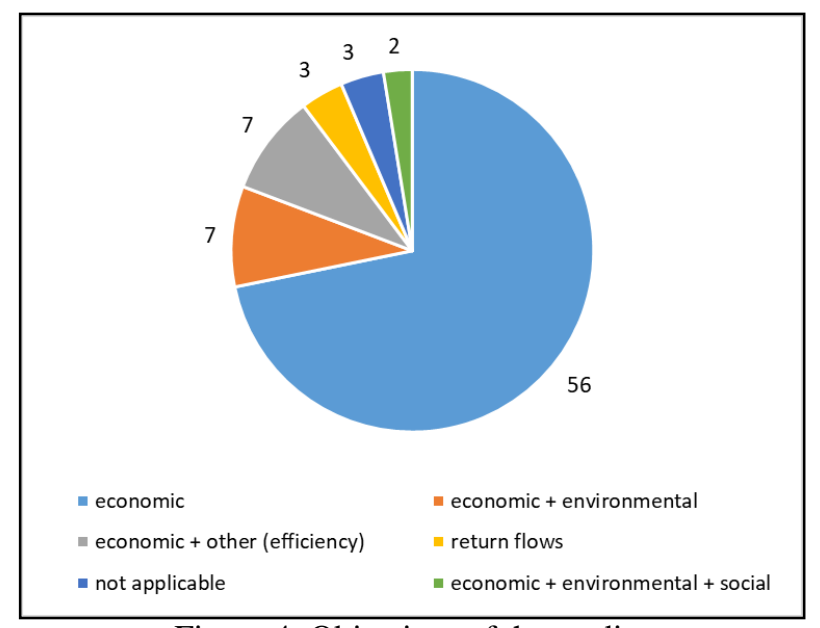

Figure 4: Objectives of the studies

Regarding the main objectives considered in the studies analyzed, Figure 4 shows that research so far has been mostly focused on the optimization of economic objectives, either alone or combined with other performance measures, such as customer satisfaction (Afshari et al. 2016, 2014), entity of return flows (Lee et al. 2007b; Niknejad and Petrovic 2014), time (Lee et al. 2013), responsiveness (Pishvaee et al. 2010), efficiency (Jayant and Kumar 2012). Seven works focus on two dimensions of sustainability, looking at both the economic and the environmental performance (Chen et al. 2017; Choudhary et al. 2015; Garg et al. 2014; Porkar et al. 2018; L.-C. Wang et al. 2013; Y. Wang et al. 2013; Zohal and Soleimani 2016), while only two include also the social dimension (Govindan et al. 2019; Nobari and Kheirkhah 2017). Finally, three of the articles reviewed measured the return flows in the CLSC as main key performance indicator (KPI) (Das and Dutta 2013a, 2013b, 2012).

Table 4: Use of deterministic and stochastic models in the methodologies applied

\begin{tabular}{|c|c|c|}
\hline Methodology & $\begin{array}{c}\text { Deterministic } \\
\text { models }\end{array}$ & $\begin{array}{c}\text { Stochastic } \\
\text { models }\end{array}$ \\
\hline $\begin{array}{c}\text { Analytical model } \\
\text { (71) }\end{array}$ & 52 & 19 \\
\hline $\begin{array}{c}\text { Simulation model } \\
(4)\end{array}$ & 0 & 4 \\
\hline $\begin{array}{c}\text { Qualitative } \\
\text { framework (3) }\end{array}$ & -- & -- \\
\hline
\end{tabular}

Considering the methodology adopted for the study, most of the articles reviewed were based on an analytical model (71), four of them used simulation to investigate the problem and only three were based on some kind of qualitative framework (Table 4). This show a clear prevalence of analytical models used to address different kinds of problems in the design and management of a CLSC with the integration of $\mathrm{F} / \mathrm{R}$ logistics. A variety of methods has been applied (e.g. mixed integer linear and non-linear models, multiobjective models, fuzzy linear programming models, 
etc.), which in $73 \%$ of cases are deterministic models, but also 19 stochastic programming models have been found. In the case of simulation modelling, the most applied technique is System Dynamics (SD), used to model the long-term behavior of the system (Das and Dutta, 2013a, 2013b, 2012), while in one case the Discrete Event Simulation (DES) has been used to model the whole SC and its flows (Jayant and Kumar 2012).

\section{THE USE OF SIMULATION FOR THE DESIGN AND MANAGEMENT OF INTEGRATED F/R LOGISTICS}

We can notice from the review that simulation modelling is not widely adopted in the context of $F / R$ logistics integration, and it has been applied so far only in works focusing on CLSC operations or on long-term behavioral analysis, while in all other cases an analytical model has been preferred. In particular, analytical models have been mostly applied to optimize the performance of the CLSC (mainly economic, but also from other perspectives), while simulation models to explore the behavior of the system in the future and the interactions between the actors and the variables analyzed. Therefore, despite the higher complexity of contexts with integrated F/R logistics, most researchers are still adopting classic analytical tools typically employed in SCM (e.g. MILP models, VRP, etc.) to analyze systems with higher variability and uncertainty, leaving the potential contribution of simulation methodologies mostly unexplored.

Each of the three main simulation methodologies available has some peculiarities that entail some strengths and weaknesses, which can make them more suitable to some kinds of problems than the others. DES models the system based on passive entities that flow through a process (a sequence of activities employing different resources). The model advances with a discrete time following a sequence of events. It is most suitable to capture low abstraction levels of a system, given its process-centric nature. On the contrary, SD is mostly used for high abstraction levels, aiming at capturing the complex dynamics resulting in a system from the interactions of entities and variables modelled as stocks and flows, with feedback structures. The model is based on a continuous time-scale through differential equations that define the causal relationships between variables. Finally, Agent Based Modelling (ABM) allows the representation of complex systems through the interaction of single intelligent entities (agents) with personal behavioral rules. Their interaction results in the final behavior of the whole system. This bottom-up approach allows reaching a wider range of abstraction, from the low level (agents' behavior) to the high level (system behavior), according to the specific needs and objectives of the modeler (Galvão Scheidegger et al. 2018). The features briefly described can be beneficial to model a context where $\mathrm{F} / \mathrm{R}$ logistic flows are integrated in a closed-loop system. Table 5 summarizes some advantages of the three techniques, related to the two main modelling problems described in section 2: the necessity to coordinate direct and reverse flows and the high uncertainty of return flows in CLSCs.

Table 5: Advantages of simulation techniques in modelling integrated F/R logistic systems

\begin{tabular}{|c|c|c|}
\hline Technique & $\begin{array}{c}\text { F/R flows } \\
\text { coordination }\end{array}$ & $\begin{array}{c}\text { Uncertainty of } \\
\text { return flows }\end{array}$ \\
\hline DES & $\begin{array}{c}\text { Captures entity } \\
\text { flows and low- } \\
\text { level processes }\end{array}$ & $\begin{array}{c}\text { Allows using } \\
\text { stochastic } \\
\text { variables }\end{array}$ \\
\hline SD & $\begin{array}{c}\text { Captures high- } \\
\text { level evolution of } \\
\text { the system }\end{array}$ & $\begin{array}{c}\text { Captures causal } \\
\text { relationships } \\
\text { between } \\
\text { variables }\end{array}$ \\
\hline ABM & $\begin{array}{c}\text { Captures } \\
\text { complexity due } \\
\text { to interactions } \\
\text { among }\end{array}$ & $\begin{array}{c}\text { Allows using } \\
\text { stochastic } \\
\text { variables }\end{array}$ \\
& individuals & \\
\hline
\end{tabular}

One of the strengths of DES is the ease of modelling processes based on activities and resources. This allows capturing the dynamics of a logistic process with a low level of abstraction, focusing on resource utilization, which is often a KPI for the process efficiency. Moreover, DES allows modelling both inputs and variables as stochastic, which gives the modeler the possibility to represent the inner uncertainty related to return flows and analyzing different possible scenarios, which is much harder to realize in an analytical model. This can also be done with ABM, which is very effective in capturing the system evolution resulting from individuals' behavior and their interactions. This can be useful in a system where complexity arises from different entities, not just from the process represented.

On the other side, SD can be more suitable when the objective is to focus on the evolution of the system during time on a high-level. The possibility to model causal loops with positive and negative feedbacks highlights the impact on the system of variations due to one or more variables. This can facilitate the representation of return flows when uncertainty is related to the interactions between variables.

One more possibility for the modeler is to adopt a hybrid simulation approach: this allows integrating different techniques, exploiting the advantages of each particular methodology where they are needed, and overcoming their limits (Brailsford et al. 2019).

\section{CONCLUSIONS}

This work focuses on how to deal with the complexity of integrated F/R logistic systems, and how simulation could support the design and management of such systems. After a brief description of the main issues to face, illustrated through three typical examples of CL systems that require the integration of $F / R$ flows, a literature review has pointed out what are the main problems addressed by researchers in this area, what are the most applied methodologies and what are the 
objectives commonly involved. The review shows, among other results, that analytical approaches are still prevalent in this area, while a few works apply simulation to support the integration of $F / R$ logistic flows, mainly to predict the system behavior in the future and its performance according to different scenarios. Starting from the analysis of the main benefits of each simulation technique, this work shows the potential of simulation methods in supporting the design and management of CLSC with integrated flows, underlining the possible advantages of this approach compared to traditional analytical ones.

Further research will be oriented to analyze each of the specific sectors identified (remanufacturing, ecommerce and WEEE) to understand how simulation can be beneficial in each of these contexts, according to their peculiarities.

\section{REFERENCES}

Afshari, H., Sharafi, M., ElMekkawy, T.Y., Peng, Q., 2016. Multi-objective optimisation of facility location decisions within integrated forward/reverse logistics under uncertainty. Int. J. Bus. Perform. Supply Chain Model. 8, 250.

Afshari, H., Sharifi, M., ElMekkawy, T.Y., Peng, Q., 2014. Facility Location Decisions within Integrated Forward/Reverse Logistics under Uncertainty. Procedia CIRP, Variety Management in Manufacturing 17, 606-610.

Al-Salem, M., Diabat, A., Dalalah, D., Alrefaei, M., 2016. A closed-loop supply chain management problem: Reformulation and piecewise linearization. J. Manuf. Syst. 40, 1-8.

Barker, T.J., Zabinsky, Z.B., 2008. Reverse Logistics Network Design: A Framework for Decision Making, in: Proceedings of the 2008 Industrial Engineering Research Conference. pp. 1290-1295.

Behmanesh, E., Pannek, J., 2018. The Effect of Various Parameters of Solution Methodology on a Flexible Integrated Supply Chain Model. Math. Probl. Eng. 2018, 1-14.

Behmanesh, E., Pannek, J., 2016. A memetic algorithm with extended random path encoding for a closedloop supply chain model with flexible delivery. Logist. Res. 9, 22.

Brailsford, S.C., Eldabi, T., Kunc, M., Mustafee, N., Osorio, A.F., 2019. Hybrid simulation modelling in operational research: A state-of-the-art review. Eur. J. Oper. Res. 278, 721-737.

Cárdenas, I., Beckers, J., Vanelslander, T., 2017. Ecommerce last-mile in Belgium: Developing an external cost delivery index. Res. Transp. Bus. Manag. 24, 123-129.

Chang, T.-S., Liao, Y.-F., 2011. Routing strategies for integrating forward distribution and reverse collection. J. Oper. Res. Soc. 62, 971-981.

Chen, Y., Liu, D., Mao, H., Tian, Y., 2008. Uncertain programming of the distribution/recovery center in forward/reverse hybrid logistics system, in: 2008 IEEE International Conference on Service
Operations and Logistics, and Informatics, pp. 3057-3062. Beijing (China).

Chen, Y.-W., Wang, L.-C., Wang, A., Chen, T.-L., 2017. A particle swarm approach for optimizing a multi-stage closed loop supply chain for the solar cell industry. Robot. Comput. Integr. Manuf. 43, 111-123.

Choudhary, A., Sarkar, S., Settur, S., Tiwari, M.K., 2015. A carbon market sensitive optimization model for integrated forward-reverse logistics. Int. J. Prod. Econ. 164, 433-444.

Chung, S.-L., Wee, H.-M., Yang, P.-C., 2008. Optimal policy for a closed-loop supply chain inventory system with remanufacturing. Math. Comput. Model. 48, 867-881.

Cilac1 Tombuş, A., Aras, N., Verter, V., 2017. Designing distribution systems with reverse flows. J. Remanufacturing 7, 113-137.

Coenen, J., van der Heijden, R.E.C.M., van Riel, A.C.R., 2018. Understanding approaches to complexity and uncertainty in closed-loop supply chain management: Past findings and future directions. J. Clean. Prod. 201, 1-13.

Das, D., Dutta, P., 2013a. Simulation Study of an Integrated Reverse Logistics in Fuzzy Environment, in: Yang, G.-C., Ao, S.-I., Huang, X., Castillo, O., IAENG Transactions on Engineering Technologies: Special Issue of the International MultiConference of Engineers and Computer Scientists 2012. Springer Netherlands, Dordrecht, 151-165.

Das, D., Dutta, P., 2013b. A system dynamics framework for integrated reverse supply chain with three way recovery and product exchange policy. Comput. Ind. Eng. 66, 720-733.

Das, D., Dutta, P., 2012. A System Dynamics Framework for an Integrated Forward-Reverse Supply Chain with Fuzzy Demand and Fuzzy Collection Rate under Possibility Constraints, in: Proceedings of the International MultiConference of Engineers and Computer Scientists (Hong Kong).

de la Fuente, M.V., Ros, L., Cardós, M., 2008. Integrating Forward and Reverse Supply Chains: Application to a metal-mechanic company. Int. J. Prod. Econ. 111, 782-792.

De Rosa, V., Gebhard, M., Hartmann, E., Wollenweber, J., 2013. Robust sustainable bi-directional logistics network design under uncertainty. Int. J. Prod. Econ. 145, 184-198.

Ding, S., 2010. Logistics Network Design and Optimization Based on Fuzzy Adaptive Differential Evolution Algorithm, in: International Conference on Biomedical Engineering and Computer Science, 1-4. IEEE, (Wuhan, China).

Djikanovic, J., Joksimovic, D., Vujosevic, M., 2015. Application of Variable Neighbourhood Search Method for Vehicle-Routing Problems in an Integrated Forward and Reverse Logistic Chain. Acta Polytech. Hung. 12, 51-70. 
Djikanovic, J., Vujosević, M., 2016. A new integrated forward and reverse logistics model: A case study. Int. J. Comput. Intell. Syst. 9, 25-35.

Dondo, R.G., Méndez, C.A., 2016. Operational planning of forward and reverse logistic activities on multi-echelon supply-chain networks. Comput. Chem. Eng. 88, 170-184.

Easwaran, G., Üster, H., 2010. A closed-loop supply chain network design problem with integrated forward and reverse channel decisions. IIE Trans. 42, 779-792.

Elahi, B., Franchetti, M., 2014. A new optimization model for closed-loop supply chain networks, in: 2014 IEEE International Technology Management Conference, 1-9. (Chicago, IL, USA).

Elia, V., Gnoni, M.G., 2015. Designing an effective closed loop system for pallet management. Int. J. Prod. Econ. 170, 730-740.

Elia, V., Gnoni, M.G., Tornese, F., 2019. Designing a sustainable dynamic collection service for WEEE: an economic and environmental analysis through simulation. Waste Manag. Res. 37, 402-411.

Elia, V., Gnoni, M.G., Tornese, F., 2018. Improving logistic efficiency of WEEE collection through dynamic scheduling using simulation modeling. Waste Manag. 72, 78-86.

Elia, V., Gnoni, M.G., Tornese, F., 2016. Measuring circular economy strategies through index methods: A critical analysis. J. Clean. Prod.

Ellen MacArthur Foundation, 2013. Towards the Circular Economy - Economic and business rationale for an accelerated transition.

Faccio, M., Persona, A., Sgarbossa, F., Zanin, G., 2011. Multi-stage supply network design in case of reverse flows: a closed-loop approach. Int. J. Oper. Res. 12, 157.

Fattahi, M., Govindan, K., 2017. Integrated forward/reverse logistics network design under uncertainty with pricing for collection of used products. Ann. Oper. Res. 253, 193-225.

Gajpal, Y., Abad, P.L., 2010. Checking the feasibility of a vehicle route in integrated supply chain transportation model. Int. J. Bus. Perform. Supply Chain Model. 2, 258-281.

Galvão Scheidegger, A.P., Fernandes Pereira, T., Moura de Oliveira, M.L., Banerjee, A., Barra Montevechi, J.A., 2018. An introductory guide for hybrid simulation modelers on the primary simulation methods in industrial engineering identified through a systematic review of the literature. Comput. Ind. Eng. 124, 474-492.

Garg, K., Sanjam, Jain, A., Jha, P.C., 2014. Designing a Closed-Loop Logistic Network in Supply Chain by Reducing its Unfriendly Consequences on Environment, in: Babu, B.V., Nagar, A., Deep, K., Pant, M., Bansal, J.C., Ray, K., Gupta, U., Proceedings of the Second International Conference on Soft Computing for Problem Solving, 1483-1498, December 28-30, 2012. New Delhi (India).
Gnoni, M.G., Mossa, G., Mummolo, G., Tornese, F., Verriello, R., 2017. Circular economy strategies for electric and electronic equipment: a fuzzy cognitive map. Environ. Eng. Manag. J. 16, $1807-$ 1817.

Govindan, K., Agarwal, V., Darbari, J.D., Jha, P.C., 2019. An integrated decision making model for the selection of sustainable forward and reverse logistic providers. Ann. Oper. Res. 273, 607-650.

Govindan, K., Soleimani, H., Kannan, D., 2015. Reverse logistics and closed-loop supply chain: A comprehensive review to explore the future. Eur. J. Oper. Res. 240, 603-626.

Gu, Q.L., Ji, J.H., 2008. An integrated logistics operational model for Remanufacturing/Manufacturing system based on the consumer market. Int. J. Logist. Syst. Manag. 4, 21.

Guide, V.D.R., Van Wassenhove, L.N., 2009. OR FORUM-The Evolution of Closed-Loop Supply Chain Research. Oper. Res. 57, 10-18.

Guo, H., Li, C., Zhang, Y., Zhang, C., Wang, Y., 2018. A Nonlinear Integer Programming Model for Integrated Location, Inventory, and Routing Decisions in a Closed-Loop Supply Chain. Complexity 2018, 1-17.

Habibi, Muh.K.K., Battaïa, O., Cung, V.-D., Dolgui, A., Tiwari, M.K., 2019. Sample average approximation for multi-vehicle collectiondisassembly problem under uncertainty. Int. J. Prod. Res. 57, 2409-2428.

Hatefi, S.M., Jolai, F., 2015. Reliable forward-reverse logistics network design under partial and complete facility disruptions. Int. J. Logist. Syst. Manag. 20, 370.

Hatefi, S.M., Jolai, F., 2014. Robust and reliable forward-reverse logistics network design under demand uncertainty and facility disruptions. Appl. Math. Model. 38, 2630-2647.

Hatefi, S.M., Jolai, F., Torabi, S.A., TavakkoliMoghaddam, R., 2016. Integrated forward-reverse logistics network design under uncertainty and reliability consideration. Sci. Iran. 23, 721-735.

Hatefi, S.M., Jolai, F., Torabi, S.A., TavakkoliMoghaddam, R., 2015. A credibility-constrained programming for reliable forward-reverse logistics network design under uncertainty and facility disruptions. Int. J. Comput. Integr. Manuf. 28, 664-678.

Hatefi, S. M., Jolai, F., Torabi, S.A., TavakkoliMoghaddam, R., 2015. Reliable design of an integrated forward-revere logistics network under uncertainty and facility disruptions: A fuzzy possibilistic programing model. KSCE J. Civ. Eng. 19, 1117-1128.

Islam, M.T., Huda, N., 2018. Reverse logistics and closed-loop supply chain of Waste Electrical and Electronic Equipment (WEEE)/E-waste: A comprehensive literature review. Resour. Conserv. Recycl. 137, 48-75. 
Jaaron, A.A.M., Backhouse, C., 2016. A systems approach for forward and reverse logistics design. Int. J. Logist. Manag.

Jalil, S.A., Hashmi, N., Asim, Z., Javaid, S., 2019. A de-centralized bi-level multi-objective model for integrated production and transportation problems in closed-loop supply chain networks. Int. J. Manag. Sci. Eng. Manag. 14, 206-217.

Jayant, A., Kumar, S., 2012. Simulation Modeling of Integrated Supply Chain Logistics Networks, in: Deep, K., Nagar, A., Pant, M., Bansal, J.C. (Eds.), Proceedings of the International Conference on Soft Computing for Problem Solving, December 20-22, 2011, Advances in Intelligent and Soft Computing. Springer India, 101-111.

Jensen, J.P., Prendeville, S.M., Bocken, N.M.P., Peck, D., 2019. Creating sustainable value through remanufacturing: Three industry cases. J. Clean. Prod. 218, 304-314.

Jinlan, L., Ni, J., 2007. A Hybrid Immune Genetic Algorithm Approach to Optimize the Integrated Forward/Reverse Logistics Network for 3PLs, in: Third International Conference on Natural Computation (ICNC 2007), IEEE, 609-613. Haikou (China).

Kaboudani, Y., Ghodsypour, S.H., Kia, H., Shahmardan, A., 2018. Vehicle routing and scheduling in cross docks with forward and reverse logistics. Oper. Res.

Keyvanshokooh, E., Fattahi, M., Seyed-Hosseini, S.M., Tavakkoli-Moghaddam, R., 2013. A dynamic pricing approach for returned products in integrated forward/reverse logistics network design. Appl. Math. Model. 37, 10182-10202.

Kim, T., Goyal, S.K., Kim, C.-H., 2013. Lot-streaming policy for forward-reverse logistics with recovery capacity investment. Int. J. Adv. Manuf. Technol. 68, 509-522.

Ko, H.J., Evans, G.W., 2007. A genetic algorithm-based heuristic for the dynamic integrated forward/reverse logistics network for 3PLs. Comput. Oper. Res. 34, 346-366.

Lee, D.-H., Bian, W., Dong, M., 2007a. Multiproduct Distribution Network Design of Third-Party Logistics Providers with Reverse Logistics Operations. Transp. Res. Rec. J. Transp. Res. Board 2008, 26-33.

Lee, D.-H., Bian, W., Dong, M., 2007b. Multiobjective Model and Solution Method for Integrated Forward and Reverse Logistics Network Design for Third-Party Logistics Providers. Transp. Res. Rec. J. Transp. Res. Board 2032, 43-52.

Lee, D.-H., Dong, M., 2008. A heuristic approach to logistics network design for end-of-lease computer products recovery. Transp. Res. Part E Logist. Transp. Rev. 44, 455-474.

Lee, H., Zhang, T., Boile, M., Theofanis, S., Choo, S., 2013. Designing an integrated logistics network in a supply chain system. KSCE J. Civ. Eng. 17, 806-814.
Lee, J.-E., Lee, K.-D., 2012. Integrated forward and reverse logistics model: a case study in distilling and sale company in Korea. Int. J. Innov. Comput. Inf. Control 8, 4483-4495.

Lee, Y.J., Baker, T., Jayaraman, V., 2012. Redesigning an integrated forward-reverse logistics system for a third party service provider: an empirical study. Int. J. Prod. Res. 50, 5615-5634.

Lin, L., Gen, M., Wang, X., 2009. Integrated multistage logistics network design by using hybrid evolutionary algorithm. Comput. Ind. Eng. 56, 854-873.

Lu, T., Zhao, X., 2010. Reverse Logistics Network Design with Consideration of Forward and Reverse Facility Integration, in: 2010 International Conference on E-Business and E-Government. IEEE, 3271-3274. Guangzhou (China).

Mehdizadeh, E., Afrabandpei, F., Mohaselafshar, S., Afshar-Nadjafi, B., 2013. Design of a multi-stage transportation network in a supply chain system: Formulation and efficient solution procedure. Sci. Iran. 20, 2188-2200.

Mitra, S., 2012. Inventory management in a twoechelon closed-loop supply chain with correlated demands and returns. Comput. Ind. Eng. 62, 870 879.

Niknejad, A., Petrovic, D., 2014. Optimisation of integrated reverse logistics networks with different product recovery routes. Eur. J. Oper. Res. 238, $143-154$.

Nobari, A., Kheirkhah, A., 2017. Integrated and Dynamic Design of Sustainable Closed-loop Supply Chain Network Considering Pricing. Sci. Iran. 6(25), 410-430.

Orendorff, A., 2019. The plague of Ecommerce return rates and how to maintain profitability. Shopify. URL:https://www.shopify.com/enterprise/ecomme rce-returns (accessed 7.3.19).

Pedram, A., Yusoff, N.B., Udoncy, O.E., Mahat, A.B., Pedram, P., Babalola, A., 2017. Integrated forward and reverse supply chain: A tire case study. Waste Manag. 60, 460-470.

Peng, Y., Yao, H., 2007. Integrated Networks of Third Party Logistics Service Providers, in: International Conference on Transportation Engineering 2007, 1530-1535. Chengdu (China).

Pishvaee, M.S., Farahani, R.Z., Dullaert, W., 2010. A memetic algorithm for bi-objective integrated forward/reverse logistics network design. Comput. Oper. Res. 37, 1100-1112.

Pishvaee, M.S., Jolai, F., Razmi, J., 2009. A stochastic optimization model for integrated forward/reverse logistics network design. J. Manuf. Syst. 28, $107-$ 114.

Ponte, B., Naim, M.M., Syntetos, A.A., 2019. The value of regulating returns for enhancing the dynamic behaviour of hybrid manufacturingremanufacturing systems. Eur. J. Oper. Res. 278, 629-645. 
Porkar, S., Mahdavi, I., Maleki Vishkaei, B., Hematian, M., 2018. Green supply chain flow analysis with multi-attribute demand in a multi-period product development environment. Oper. Res.

Radhi, M., Zhang, G., 2019. Optimal cross-channel return policy in dual-channel retailing systems. Int. J. Prod. Econ. 210, 184-198.

Rezaei, S., Kheirkhah, A., 2017. Applying forward and reverse cross-docking in a multi-product integrated supply chain network. Prod. Eng. 11, 495-509.

Roghanian, E., Kamandanipour, K., 2013. A fuzzyrandom programming for integrated closed-loop logistics network design by using priority-based genetic algorithm. Int. J. Ind. Eng. Comput. 4, 139-154.

Ross, A., Khajehnezhad, M., Otieno, W., Aydas, O., 2017. Integrated location-inventory modelling under forward and reverse product flows in the used merchandise retail sector: A multi-echelon formulation. Eur. J. Oper. Res. 259, 664-676.

Saarijärvi, H., Sutinen, U.-M., Harris, L.C., 2017. Uncovering consumers' returning behaviour: a study of fashion e-commerce. Int. Rev. Retail Distrib. Consum. Res. 27, 284-299.

Sahyouni, K., Savaskan, R.C., Daskin, M.S., 2007. A Facility Location Model for Bidirectional Flows. Transp. Sci. 41, 484-499.

Shulman, J.D., Coughlan, A.T., Savaskan, R.C., 2009. Optimal Restocking Fees and Information Provision in an Integrated Demand-Supply Model of Product Returns. Manuf. Serv. Oper. Manag. 11, 577-594.

Soleimani, H., Seyyed-Esfahani, M., Shirazi, M.A., 2016. A new multi-criteria scenario-based solution approach for stochastic forward/reverse supply chain network design. Ann. Oper. Res. 242, 399421.

Tan, Y., Guo, C., 2019. Research on Two-Way Logistics Operation with Uncertain Recycling Quality in Government Multi-Policy Environment. Sustainability 11,882 .

van Loon, P., Delagarde, C., Van Wassenhove, L.N., Mihelič, A., 2019. Leasing or buying white goods: comparing manufacturer profitability versus cost to consumer. Int. J. Prod. Res. 1-15.

Wang, L.-C., Chen, T.-L., Chen, Y.-Y., Chen, Y.-W., Wang, A., 2013. Closed-Loop Sustainable Supply Chain Design Under Uncertainties, in: Azevedo, A. (Ed.), Advances in Sustainable and Competitive Manufacturing Systems. Springer International Publishing, Heidelberg, 799-812.

Wang, M., Di, W.-M., 2010. A location-inventory model for integrated forward/reverse logistics network design, in: 2010 International Conference on Management Science \& Engineering 17th Annual Conference Proceedings, IEEE, 299-304, Melbourne (Australia).

Wang, X., Zhao, L., 2009. Network Design of Reverse Logistics Intergrated with Forward Logictics, in:
2009 Asia-Pacific Power and Energy Engineering Conference, IEEE, 1-4, Wuhan (China).

Wang, Y., Lu, T., Zhang, C., 2013. Integrated Logistics Network Design in Hybrid Manufacturing/ Remanufacturing System Under Low-Carbon Restriction, in: Zhang, Z., Zhang, R., Zhang, J., LISS 2012. Springer Berlin Heidelberg, 111-121.

Wassan, N., Nagy, G., 2014. Vehicle Routing Problem with Deliveries and Pickups: Modelling Issues and Meta-heuristics Solution Approaches. Int. J. Transp. 2, 95-110.

Xie, R.H., Qiu, Z.Q., Zhang, Y.Y., 2007. A New Heuristics for VRP with Simultaneous Delivery and Pick-Up. Presented at the International Conference on Transportation Engineering, Southwest Jiaotong University, Chengdu (China).

Yazdi, A.A., Honarvar, M., 2015. A Two Stage Stochastic Programming Model of the Price Decision Problem in the Dual-channel Closed-loop Supply Chain. Int. J. Eng. 28.

Zhang, T., Chaovalitwongse, W.A., Zhang, Y., 2014. Integrated Ant Colony and Tabu Search approach for time dependent vehicle routing problems with simultaneous pickup and delivery. J. Comb. Optim. 28, 288-309.

Zhou, X., 2015. A Random Multi-objective Model on Integrated Logistics. World J. Model. Simul. 11, $3-15$.

Zhou, X., Xu, J., 2009. A class of integrated logistics network model under random fuzzy environment and its application to Chinese beer company. Int. J. Uncertain. Fuzziness Knowl. Based Syst. 17, 807831.

Zohal, M., Soleimani, H., 2016. Developing an ant colony approach for green closed-loop supply chain network design: a case study in gold industry. J. Clean. Prod. 133, 314-337.

\section{AUTHORS BIOGRAPHY}

Giulio Paolo Agnusdei is a graduate student at the Department of Innovation Engineering of the University of Salento. His research focuses on the design and management of last-mile logistic systems.

Maria Grazia Gnoni, PhD, is an Assistant Professor at the Department of Innovation Engineering of University of Salento. Her research interests focus on designing sustainable waste management systems, green supply chain and processes and lean safety.

Fabiana Tornese, $\mathbf{P h D}$, is a post-doctoral researcher in the Department of Innovation Engineering in the University of Salento. Her research focuses on supply chain management and logistics, in particular on the impact of circular economy models on reverse logistics in the industrial and service sector. 